\title{
The ACID-Survey: Methodology and Design of an Online Survey to Assess Alcohol and Recreational Cocaine Use and its Consequences for Traffic Safety
}

\author{
J.C. Verster ${ }^{*}, 1$ Y. Kuerten ${ }^{1}$, B. Olivier ${ }^{1}$ and M.W. van Laar $^{2}$ \\ ${ }^{I}$ Utrecht University, Utrecht Institute for Pharmaceutical Sciences, Faculty of Science, Section Psychopharmacology, \\ Utrecht, The Netherlands \\ ${ }^{2}$ Trimbos Institute, Netherlands Institute of Mental Health and Addiction, Utrecht, The Netherlands
}

\begin{abstract}
Studies report consistently that cocaine and alcohol is currently the most upcoming drug combination in Europe. The Alcohol and Cocaine Impaired Drivers (ACID)-survey was conducted among Dutch partygoers (18-30 years old) to establish who will drive a car after using alcohol and/or cocaine and why. The purpose of this paper is to describe the methodology and design of the ACID-survey. The online survey comprised a large number of questions on demographics and respondent characteristics, alcohol and drug use, reasons for driving after using cocaine, and prevention methods. A total of 64,575 subjects read the invitation and 10,153 started the survey (15.7\%). N=7,834 subjects completed the survey and met all criteria to be included in the analyses. The ACID-survey has provided a valid and reliable data set, representative for Dutch partygoers. The employed methodology showed to be a cost efficient way to monitor substance use and other risk behaviors in a high risk group of young adults.
\end{abstract}

Keywords: ACID-survey, cocaine, alcohol, drugs, driving, traffic safety.

\section{INTRODUCTION}

The ACID-survey was conducted among Dutch partygoers (18-30 years old) to establish who will drive a car after using alcohol and/or cocaine and why. The acronym ACID refers to Alcohol- and Cocaine Impaired Drivers. This paper describes and discusses the methodology and design of the ACID-survey.

\section{ALCOHOL, RECREATIONAL DRUG USE AND DRIVING}

Studies report consistently that cocaine and alcohol is currently the most upcoming drug combination in Europe used by 3 to $30 \%$ of the general population $[1,2]$. Recent European studies of cocaine-impaired drivers involved in traffic accidents report percentages up to 10\% [1-3]. It should be noted that these percentages are from the general population and that cocaine use is much more prevalent among certain subgroups than others. For example, partygoers show a much higher percentage of cocaine use [4]. Recent Dutch data shows that the last-month prevalence of cocaine use among young partygoers ranges from $3 \%$ to $19 \%$ [5]. Surveys show that about $3 \%$ to $36 \%$ of recreational drug users who have visited clubs or rave parties attest that they drive a car after using cocaine or other drugs [6-8].

Cocaine is thought to promote wakefulness and to counteract the sedative and negative psychomotor effects of alcohol. In fact, research shows that cocaine reduces alcohol-

\footnotetext{
*Address correspondence to this author at the Utrecht University, Utrecht Institute for Pharmaceutical Sciences, Faculty of Science, Section Psychopharmacology, PoBox 80082, 3508TB, Utrecht, The Netherlands. Tel: +31 30253 6909, Fax: +31 30253 7900, E-mail: j.c.verster@uu.nl
}

induced sedation and/or feelings of drunkenness and also partially antagonizes objective performance deficits observed with alcohol alone [9]. This is particularly troubling for driving and risk-taking decisions following co-use, as it may increase the likelihood of driving due to misperceived increases in sobriety and psychomotor coordination. Acute administration of cocaine does not only enhance feelings of euphoria and increase alertness, but has also been reported to increase self-confidence, impulsivity and aggression, especially at higher doses and in combination with alcohol $[6,7,10,11]$. Such effects may result in enhanced risk taking, reckless driving and loss of control of the vehicle, which is consistent with accident data from police records of cocaine-related driving fatalities [12]. Three recent epidemiological case-control studies confirm that cocaine users are more likely to cause accidents than drug free drivers [1315]. For example, Soderstrom et al. [13] showed that drivers testing positive for cocaine were about two times more likely to be culpable for their crash than drivers testing negative for cocaine. Current designated driver programs primarily focus on alcohol-impaired driving [16]. In order to develop effective prevention methods it is important to determine who is likely to be a cocaine-impaired driver (in terms of demographic and personality characteristics) and the motivation and reasons behind their behavior.

\section{RATIONALE FOR THE ACID-SURVEY}

The ACID-survey focuses on young adult partygoers (1830 years old), as this group is over-represented in (1) the numbers of reported traffic accidents, (2) the use of cocaine/alcohol, and (3) the frequency of detection of driving under the influence of drugs. Both men and women will participate in the study, since it is likely that there are gender 
differences in drug expectancies and reasons for driving under the influence of drugs [17].

\section{HYPOTHESES AND MAIN RESEARCH QUESTIONS}

Our primary hypothesis is that:

There are demographic and personality differences between people who drive a car after cocaine/alcohol use and those who do not.

We further hypothesize that besides pragmatic reasons (there is no alternative transportation), subjects who drive a car after cocaine/alcohol use have:

\section{(a) A high risk taking profile.}

(b) Do not foresee/acknowledge the risks involved in driving after cocaine/alcohol use. Those who do not drive after cocaine/alcohol use are thought to have the opposite profile.

\section{ONLINE SURVEYS: METHODOLOGICAL CONSI- DERATIONS}

Face-to-face interviews and traditional paper-pencil surveys are time-consuming and require extensive labor by a team of (trained) personnel. In addition, if the data are not gathered electronically often a lot of time and effort is required to enter data into an electronic database before statistical analyses can take place. Transcription errors may occur during this process. When conducting an online survey, time, labor and money is saved because the respondents enter the data themselves. In a short time a large sample size can be achieved at minimal costs. Response rates may be higher using the Internet, because the respondent often has a choice of time to complete the survey. Also, because the interviewer is not present when respondents complete an online survey the respondent may be less likely to give socially desirable answers when compared to phone interviews or face-to-face surveys. In sum, online surveys seem a quick and efficient way to collect data from large samples.

Unfortunately, surveys can have several disadvantages that may affect the validity and reliability of the dataset. Four issues are of particular importance, including coverage error, sampling error, non response bias and measurement error. These issues can affect both paper and online surveys.

\section{Coverage Error}

Coverage error occurs when the sample does not adequately match the population. This may be caused by the fact that often it is not possible to draw a random sample when performing online surveys. In many instances, everybody who visits a website can complete the survey. When the survey is completed by 'uncontrolled' selfselected website visitors (i.e., a convenience sample) this will certainly bias the outcome of the survey in that it will be difficult to generalize findings. Another issue that may contribute to coverage error is that certain groups in the population may have no access to Internet facilities (e.g., the poor) or limited computer knowledge (e.g., the elderly). It is therefore important to determine whether online surveys are suitable for the population one wants to study (in this case partygoers). Also, it should be ensured that a person belongs to the intended population and that participants complete the survey only once. Coverage error affects the representativeness of the sample and is often the primary criticism of online survey research [18]. However, comparative research showed that when controlling for unlimited survey access the representativeness of samples obtained by online and paper version surveys is similar [1922].

\section{Sampling Error}

In case of sampling error, those who are invited to complete the survey do not match the target population. For example, if one wants to conduct a survey to determine the most favored birth control pill it is not useful to invite all women. Certain women should not be part of the sample (e.g., young children or post-partum women), whereas others should (e.g., fertile women). In less obvious instances, pilot surveys often can be helpful to determine the correct sample.

\section{Non Response and Non Response Bias}

A common observation in survey research is that the bigger the population the smaller the response rate will be. Response rates to internet surveys are generally lower when compared to paper and telephone surveys [23], which increases the risk of non-response bias [24].

Not everybody who is invited will actually complete the survey. Possible differences between those who completed the survey and those who did not may bias the outcome of the survey. Non response bias is of particular concern when surveys aim to measure prevalence estimates (e.g., percentages and proportions). In case of non response bias, certain subgroups may be over-represented or underrepresented in the obtained sample which may cause obtained prevalence estimates to differ from the population. In contrast, when - as in our survey - the primary purpose of a survey is to examine associations between variables non response bias is of much less concern [25]. Unfortunately, in most studies little information is available about non responders. Therefore the impact of non response is often difficult (or not at all) to quantify.

Reasons for non response are diverse and may vary from having no time or interest to complete the survey to a boring topic, a lengthy survey, or difficult wording of questions. For online surveys, technical problems may limit Internet access and significantly reduce the response rate. An advantage of online surveys that may increase response rate is that subjects generally feel more anonymous when compared to paper surveys. Moreover, this may enhance reliability of answers to questions on sensitive issues or stigmatized behaviors, as illegal drug use may be. Several techniques can be applied to reduce non response error, including incentives for completing the survey, having an attractive layout, and keeping the survey as short as possible. If data is available on demographic and other variables of the sample, these can be compared with those who actually completed the survey. That way, the possible impact of non response error can be judged.

\section{Measurement Error}

The validity and reliability of the survey content has a great impact on the quality and correctness of the study 
outcome. Incorrect or incomplete questions or poor question wording may lead to misunderstanding and wrong answers. A good way to prevent these errors is to pilot a survey among a small group of potential respondents. Also, including validated and reliable scales in the survey prevent the risk of measurement error.

In conclusion, various issues can affect the validity and reliability of surveys. The ACID survey aimed to minimize the above mentioned methodological limitations.

\section{SURVEY CONTENT}

A flow chart of the survey content is shown in Fig. (1). The survey consisted of 2 parts. Part 1 concerned questions on alcohol and drug use and driving. After completing demographic questions, participants completed a different set of questions depending on whether they used alcohol and/or drugs during the past year. This is shown in the Flowchart (see Fig. 1).

Part 2 consisted of questions on mood and personality. Participants could choose whether to stop after Part 1, or to continue with Part 2.

\section{Demographics}

Demographic variables were collected including age, gender, level of education, and music preferences.

\section{Risk Taking Behavior Questionnaire (RT-18)}

An 18-item questionnaire [26], the RT-18, was developed from items of subscales on Impulsiveness and Venturesomeness from the IVE questionnaire [27, 28], Novelty Seeking from the Temperament and Character Inventory (TCI) [29, 30], and Impulsive Sensation Seeking
(ImpSS) from the Zuckerman Kuhlman Personality Questionnaire [31]. Questions of the RT-18 can be answered by 'yes' and 'no' or 'correct' and incorrect'. Scores are 0 or 1 point per question, adding up to a sum score ranging from 0 to 18 .

\section{Drinking Behavior, Smoking, Drug Use}

Participants rated their alcohol, nicotine and drug use during the past year. Frequency of past year drug use (including cannabis, cocaine, speed, amphetamines, GHB, ecstasy, ketamine, LSD and magic mushrooms) was recorded. Frequency of past year drug use was scored as "never", "sporadic", "monthly" or "weekly" or "daily". The number of alcoholic drinks per day was recorded by using a time-line-follow back method for the past week [32]. Nicotine use over the past year was scored as "never", "sporadic", "often", or "always". Those who acknowledged using alcohol and drugs during the past year also rated the type of drug(s) and number of alcoholic drinks they had on their last dance event.

\section{5-Shot Questionnaire}

The 5-Shot questionnaire is composed by 2 questions of the AUDIT and 3 questions of the CAGE concerning alcohol use and its consequences $[33,34]$. Scores range from 0 to 7. A score of 2.5 or greater indicates possible alcohol misuse and the need for further evaluation.

\section{Brief Young Adult Alcohol Consequences Questionnaire}

The Dutch version of the Brief Young Adult Alcohol Consequences Questionnaire (BYAACQ) consists of 24 possible consequences of alcohol consumption that can be answered by 'yes' or 'no', depending on whether or not the

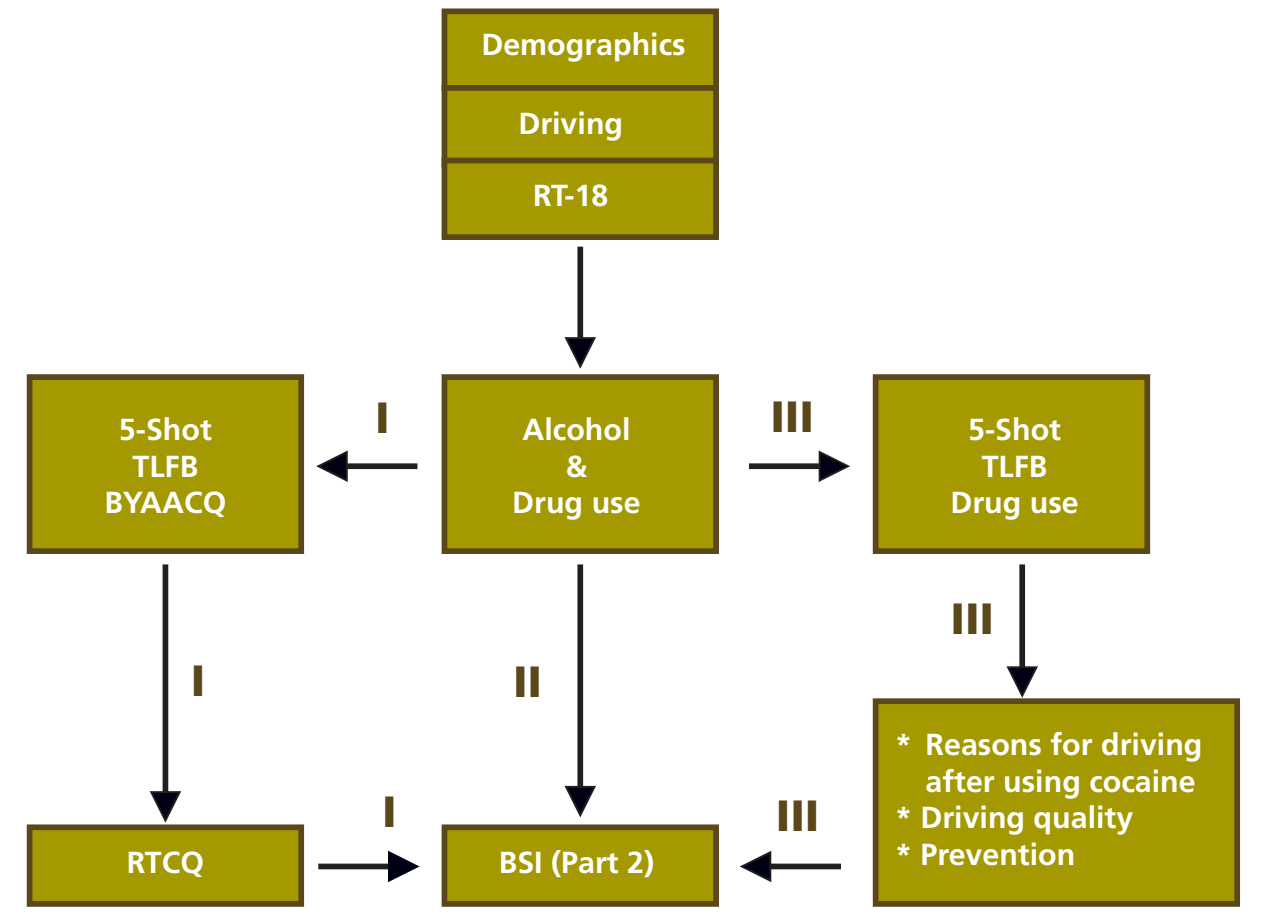

Fig. (1). Flowchart of the survey. Most important topics and groups of questions are summarized. Abbreviations: TLFB = Time Line Follow Back, BYAACQ = Brief Young Adult Alcohol Consequences Questionnaire, RTCQ = Readiness To Change Questionnaire, BSI = Brief Symptom Inventory. I = questions answered by those who consume alcohol but not use drugs, II = questions answered by those who do not use alcohol and drugs, III = questions answered by those who use drugs (with or without alcohol). 
statement was applicable to the subject during the past year $[35,36]$. The outcome score ranges from 0 to 24 . The Dutch BYAACQ has a high reliability and validity: Cronbach's Alpha was 0.816, and BYAACQ scores correlated significantly with AUDIT-PC scores $(r=0.747)$. In addition, BYAACQ scores correlated significantly $(\mathrm{p}<0.01)$ with various drinking variables, including drinking onset age, drinking days per week, alcoholic drinks per week, and number of drinks on a regular night out [36].

\section{Readiness to Change Questionnaire}

The Readiness to Change Questionnaire (RTCQ) comprises 12 questions about reducing drinking [37, 38]. Each question can be answered on a 7-point Likert scale, ranging from "totally disagree" $(-3)$ to "totally agree" $(+3)$ around a neutral midpoint (0). Scores can be categorized into 3 stages of reduced drinking: (1) pre-contemplation, (2) contemplation, and (3) action. We followed the methodology of Rollnick and colleagues [39]. Participants were designated to a particular stage if they scored positive on that stage, but negative on the two other stages. A single control question was included in the survey, to check the subject's reliability of answering.

\section{Driving History}

Subjects were asked whether they possess a drivers license and for how many years. The total kilometers per year driven and number of accidents during the past 3 years were recorded. Subjects could indicate the nature of the accident (bodywork damage, crash without injury/hospital visit, crash with injury/hospital visit) and the possible cause of the accident (weather conditions, other traffic, sleepiness, other traffic, alcohol, cocaine, alcohol and cocaine, other drugs, and other causes).

\section{Driving Style}

Subjects rated five dimensions of their regular driving style on a 7-point Likert scale, ranging from -3 (totally disagree) to +3 (totally agree) around a neutral midpoint (0), including dangerous-safe, irresponsible-responsible, unpredictable-predictable, tensed-relaxed, and aggressive-not aggressive [40].

\section{Driving After Cocaine Use}

Specifically, those who acknowledged using cocaine during the past year were asked whether or not they drove a car after using cocaine (with or without alcohol). If they answered affirmative, they were questioned about the last dance event they left by car. The grams of cocaine as well as the number of alcoholic consumptions for that evening were recorded, as well as the time before driving. They also completed the driving style scale [40] to judge their driving of that particular night on the five dimensions described above.

\section{Reasons for Driving After Using Cocaine}

Twelve reasons for driving after using cocaine were listed and could be answered by yes or no. Reasons varied from "it is cheaper than public transportation" to "It is not unsafe, I am perfectly capable of driving" and "cocaine prevents me of getting drunk". An additional open answering possibility was available for respondents to mention additional reasons or comments. In addition, participants rated the importance of each reason for driving on a 5 point scale, ranging from 'very unimportant' (1) to 'very important' (5). In a text box, respondents could comment on the question or give further explanation for their choices.

\section{Prevention of Cocaine-Impaired Driving}

Five statements were presented to the participants. The statements concerned traffic safety knowledge (e.g., increased risk of having an accident after using cocaine), and methods of repression (effect of possible fines and law enforcement)). Participants could answer on a 7-point Likert scale, ranging from 'completely disagree' (1) to 'completely agree (7) around a 'neutral' midpoint (4).

\section{Brief Symptom Inventory (BSI)}

The BSI [41, 42] is the short version of the SCL-R-90, which measures the same dimensions. Items for each dimension of the BSI were selected based on a factor analysis of the SCL-R-90, with the highest loading items on each dimension selected for the BSI [43, 44]. The BSI consists of 53 items covering nine symptom dimensions. For this survey we included 7 subscales, measuring Cognitive functioning, Depression, Anxiety, Hostility, Phobic anxiety, Paranoid ideation and Psychoticism. To limit the length of the survey scales measuring somatization and interpersonal sensitivity were omitted, since they deemed less relevant for addressing the main research questions. Respondents rank each feeling item (e.g., "your feelings being easily hurt") on a 5-point scale ranging from 0 (not at all) to 4 (extremely). Rankings characterize the intensity of distress during the past week. Mean score for each symptom dimension is computed.

\section{VALIDITY AND RELIABILITY}

\section{Prevention of Coverage Error}

In order to have a representative sample of recreational cocaine users aged 18 to 30 years old, we chose to recruit our sample among partygoers. Interviews at a local rave-club among 79 partygoers confirmed that the prevalence of drugimpaired driving is much higher among partygoers when compared to the general population. Of those with a driver's license $(81 \%), 67.7 \%$ (42 of 62 ) of partygoers confirmed driving after using drugs. An uncontrolled explorative Internet poll on www.Partyflock.nl (October 2008) revealed that about $21 \%$ of 33.973 respondents acknowledged driving a car after using cocaine (with or without alcohol). The interviews and poll confirm that partygoers are an excellent population to recruit recreational cocaine users who may or may not drive a car.

To determine if those who visit www.Partyflock.nl are representative for the whole population of partygoers we performed a pilot study at a popular Dutch dance event (November 22, 2008). Approximately one in fifteen out of 30,000 partygoers was interviewed at the entrance of the dance event $(\mathrm{N}=2,000)$. Only 39 people refused; short interviews were held among 1,961 randomly selected subjects. They were asked whether they had visited the Partyflock website during the past year to get information about upcoming dance events. The vast majority, $85 \%$, responded that they did, illustrating the representativeness of Partyflock. People who did not look at this website used a 
variety of different Internet sources, radio and TV advertisement, or heard about the party from friends. Only $3.3 \%$ reported looking on the website of the organization of this dance event (i.e. the second most frequently mentioned website). Hence, this pilot survey showed that visitors of www.Partyflock.nl comprise a representative sample of partygoers with minimal coverage error.

Regarding Internet use and accessibility, data from Statistics Netherlands indicated that Internet is widely available and used in The Netherlands. In 2008, 99\% of the population of 15-35 years old) have access to the Internet [45], and all of them reported having used the Internet during the past 3 months. Given these percentages, limited Internet access is not an issue that may cause any coverage error.

\section{Prevention of Sampling Error}

In order to prevent sampling error, we decided to invite the whole Partyflock population aged 18-30 years old $(\mathrm{N}=209.520)$ instead of drawing a random sample. This was also done because it contributes to obtaining a bigger sample size. Given the limited period of exposure of the invitation banner on the personal webpage (i.e. 9 days) this was important. Although Internet use among our population is extremely high there is no guarantee that the whole Partyflock population will check their personal webpage within this short time period.

\section{Prevention of Non Response Bias}

Non response bias may occur if there are differences between those who completed the survey and those who did not. To test whether the respondents were representative for the whole Partyflock population, demographic variables (age and gender) and music preference were compared (see Results section).

In order to increase the response rate (and thus decrease the risk of non response bias) incentives were available for those who completed the survey. After completion of Part 1 of the survey, respondents could win one of two iPhones after completion of Part 2, respondents could win one out of ten iTunes Music Store Cards. In addition, we tried to keep the survey as short as possible and used a simple, userfriendly yet attractive lay-out. A progress indicator bar at the bottom of each page informed respondents about the percentage of the survey that was completed.

\section{Prevention of Measurement Error}

To prevent measurement error, most questions were taken from validated Dutch versions of questionnaires such as the 5-Shot, BYAACQ, BSI, RT18, and the RTCQ. These questionnaires have proven to be reliable and valid. Because there is always a chance that newly developed questions have incorrect, poor, difficult or ambiguous wording, before starting the survey its content was tested among $\mathrm{N}=100$ potential respondents. According to their comments and suggestions, the survey was improved. In addition, answering possibilities and content of vital questions (e.g., reasons for driving after cocaine and possible ways to prevent this) were constructed based on pilot study results (e.g., rave-club interviews in October).

\section{SAMPLE SIZE}

Aim of the ACID-survey was to recruit at least $\mathrm{N}=2,000$ recreational cocaine users between 18 and 30 years old. This number of users was based on the formula by Peduzzi et al [46], stating that 15 respondents are required for each predictor variable. In order to calculate the minimal required sample size needed for logistic regression analysis the following formula was used: (number of independent predictor variables) $\times 15 /$ (expected response rate to dependent variable). Based on our explorative Internet poll at www.Partyflock.nl we expected $21 \%$ of respondents to drive after cocaine use (the dependent variable). Given 28 independent variables, applying the formula $[(28 \times 15) / 0.21]$ revealed that the minimal required sample size equals $\mathrm{N}=2000$.

\section{ETHICAL CONSIDERATIONS}

After clicking the survey invitation banner on their personal (private) webpage, subjects were transferred to the survey. The first webpage comprised a short description of the purpose and content of the survey, and it was stated that participation was voluntary and that information would be treated confidential and that participants remained anonymous. Subjects could give informed consent to start the survey through use of the click-box to go the start page. No approval of the Medical Ethical Review Board was required to conduct this survey. The survey was financially supported by internal funding of Utrecht University, The Netherlands.

After completion (or premature stopping) the survey, on the final screen participants were referred to the website of the Trimbos Institute (www.trimbos.nl) if they required information about alcohol and drug use. There was also a possibility to submit comments about the survey (content and set up) to the researchers. Informed Consent was asked to approach respondents for possible follow-up studies. If agreed, they could submit their e-mail address. For possible follow-up studies, participants' data was labeled by a unique identification number.

\section{DATA COLLECTION}

All members of www.Partyflock.nl between 18 and 30 years old $(\mathrm{N}=209.520)$ received an invitation on their personal (private) webpage to complete the survey. The invitation was posted from December 12 to 20, 2008. When they clicked on the invitation banner they were redirected to www.surveymonkey.com to obtain Informed Consent and start the survey. Data was collected online and could be transferred to excel format. Data was edited and recoded to summarize measurements and meet the requirements to be used in SPSS.

\section{DATA SELECTION}

We used a conservative approach to ensure a final set of valid data. Respondents were excluded on a number of criteria. For example, to control for invalid responses the survey contained duplicate questions that were either negatively or positively stated. If answers were not consistent, the respective surveys were omitted from the 


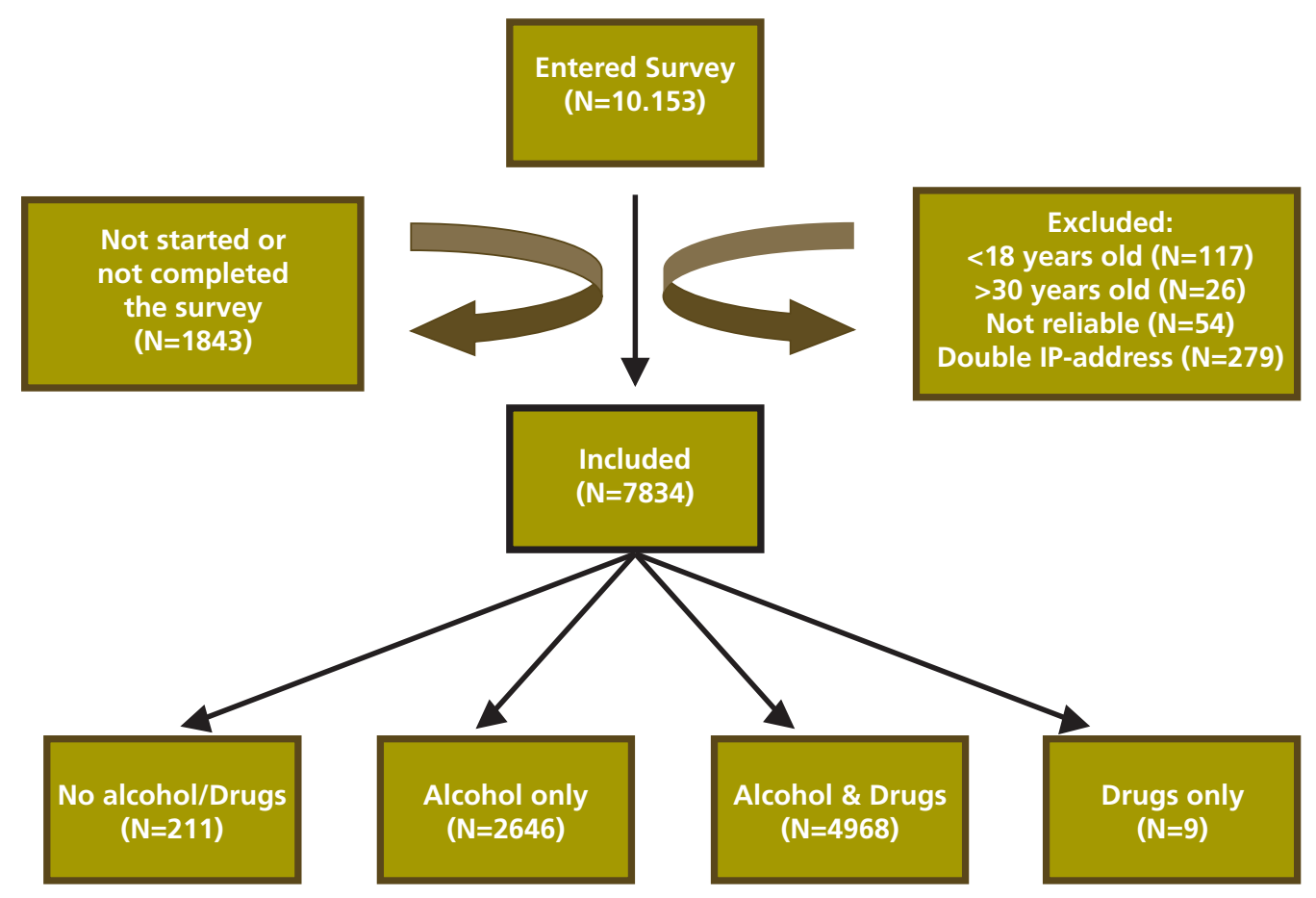

Fig. (2). Flowchart of included and excluded subjects.

analyses. At the end of the survey, subjects were asked if they have honestly and correctly answered all questions of the survey.

Total time to complete the survey was recorded. It was estimated that the survey should take approximately 5 to 10 minutes to complete. Surveys that were completed within 3 minutes were excluded from the analyses. Time of day of survey completion was recorded as well. Surveys completed between 2 am and 7 am were regarded as unreliable and excluded from the analyses.

To exclude multiple submissions, those surveys submitted from the same computer were omitted. IPaddresses (i.e. the identification number of a unique computer) were available of those who completed the survey and were checked to indentify multiple entries. Although this is a conservative method with the risk of losing valid responses (e.g., two people sharing one computer), it is the best way to ensure valid data. Those using a similar e-mail address to win an incentive were excluded as well.

Age was checked to include only surveys completed by participants aged 18 to 30 years old. Surveys were excluded as 'incomplete' when no questions were answered or only the demographic variables of the first few questions were obtained.

\section{RESULTS}

\section{Response Rate and Final Data Set}

A total of 64,575 subjects read the invitation and 10,153 started the survey $(15.7 \%)$. N=7,834 subjects completed the survey and met all criteria to be included in the analyses. Reasons for including and excluding subjects are summarized in Fig. (2).

\section{Representativeness of the Sample}

To examine the representativeness of the sample, we compared baseline variables (age, gender, and music preferences) with the total Partyflock population. A summary of this data is given in Fig. (3).

From Fig. (3) it is evident that our sample matches with the whole Partyflock population. There is no significant difference between age and gender between the sample and the population. Fig. (3) shows that percentages of several music style preferences significantly differ between our sample and the Partyflock population. This may be caused by the fact that Partyflock collected this data before the survey was conducted (i.e., when someone becomes a member). Nevertheless, although percentages change, the overall listing of our sample and the Partyflock population is comparable, and differences are generally within $10 \%$. Unfortunately, no other variables of the Partyflock population are available to examine the impact of possible non response on the representativeness of our sample.

\section{DISCUSSION}

The ACID-survey has provided a valid and reliable dataset useful for studying associations between subject demographics and characteristics and the various causes and consequences of alcohol and recreational drug use, including reasons for driving after using cocaine and possible ways of prevention. The employed methodology showed to be a cost efficient way to monitor substance use and other risk behaviors in a high risk group of young adults. Future online surveys can adopt the followed strategy. In addition, the online survey enables us to perform follow-up research and compare this data with the current data set. 

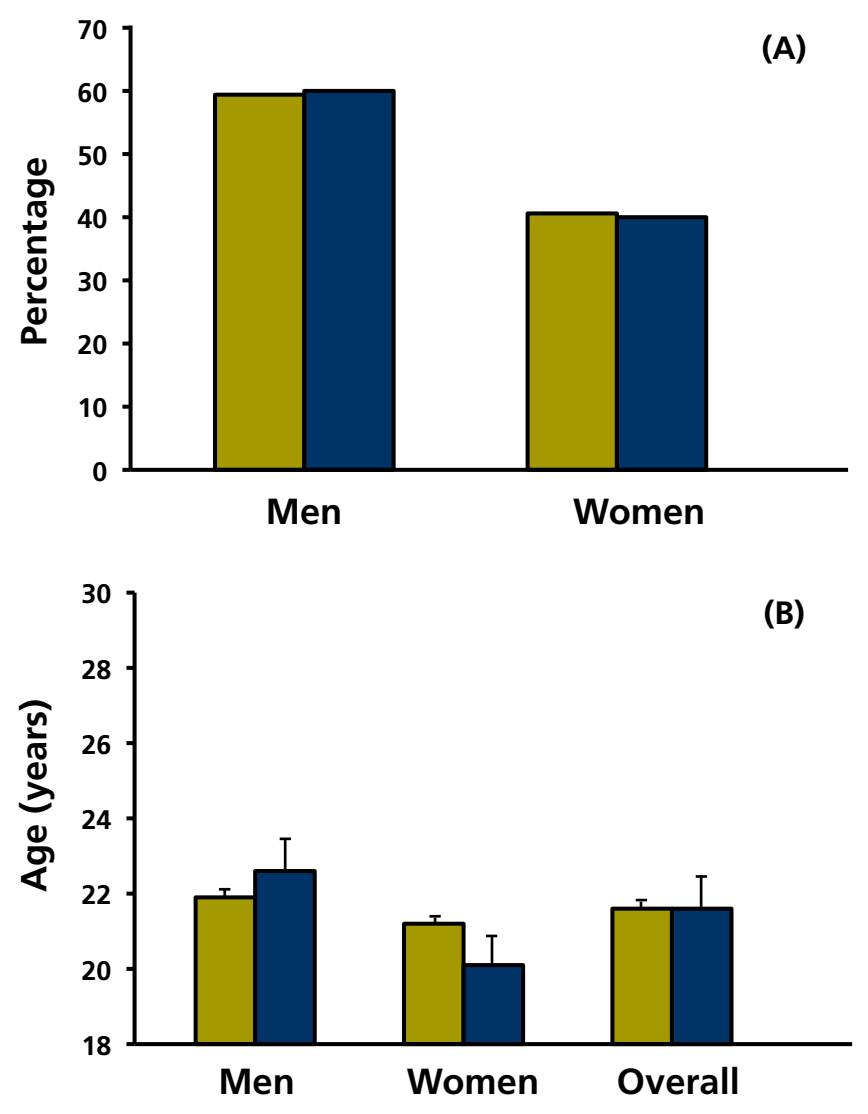

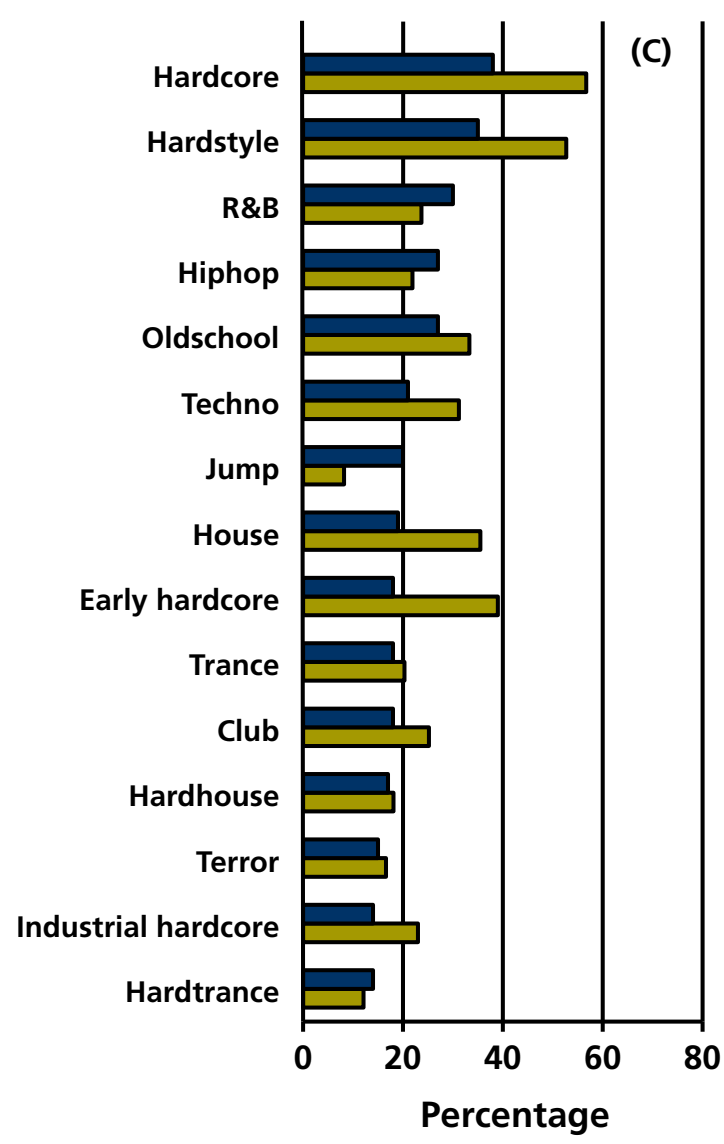

Fig. (3). Comparison of baseline characteristics of the survey sample (blue bars) with the total population of Partyflock (green bars). Gender (A), Age (B), and music preference (C).

\section{ACKNOWLEDGEMENTS}

The ACID-survey was financially supported by Utrecht University. The authors have no conflicts of interest to disclose. We thank Partyflock and its members for their participation in the ACID-survey.

\section{REFERENCES}

[1] Siliquini R, Chiado Piat S, Gianino MM, et al. Drivers involved in road traffic accidents in Piedmont Region: psychoactive substances consumption. J Prev Med Hyg 2007; 48: 123-8.

[2] Holmgren A, Holmgren P, Kugelberg FC, et al. Predominance of illicit drugs and poly-drug use among drug-impaired drivers in Sweden. Traffic Inj Prev 2007; 8: 361-7.

[3] Papadodima SA, Athanaselis SA, Stefanidou ME, et al. Driving under the influence in Greece: a 7-year survey (1998-2004). Forensic Sci Int 2008; 174: 157-60.

[4] European Monitor Centre for Drugs and Drug Addiction. Annual Report: the state of the drugs problem in Europe. Luxembourg: Office for Official Publications of the European Communities 2008

[5] Nationale Drug Monitor Jaarbericht 2007. Trimbos Institute, Utrecht, The Netherlands 2008.

[6] Riley SC, James C, Gregory D, et al. Patterns of recreational drug use at dance events in Edinburgh, Scotland. Addiction 2001; 96: $1035-47$.

[7] Degenhardt L, Dillon P, Duff C, et al. Driving, drug use behaviour and risk perceptions of nightclub attendees in Victoria, Australia. Int J Drug Policy 2006; 17: 41-6.

[8] Roomer A, Akouele T. Alcohol, Drugs \& Verkeer: een onderzoek onder bezoekers van coffeeshops en grootschalige discotheken in de regio Nijmegen (Nederland) -Kleve (Duitsland) De Grift 2006.
[9] Farré M, de la Torre R, González ML, et al. Cocaine and alcohol interactions in humans: neuroendocrine effects and cocaethylene metabolism. J Pharmacol Exp Ther 1997; 283: 164-76.

[10] Kelly E, Darke S, Ross J. A review of drug use and driving: epidemiology, impairment, risk factors and risk perceptions. Drug Alcohol Rev 2004; 23: 319-44.

[11] Fillmore MT, Rush CR, Hays L. Acute effects of oral cocaine on inhibitory control of behavior in humans. Drug Alcohol Depend 2002; 67: 157-67.

[12] Schwilke EW, Sampaio dos Santos MI, Logan BK. Changing patterns of drug and alcohol use in fatally injured drivers in Washington State. J Forensic Sci 2006; 51: 1191-8.

[13] Soderstrom CA, Dischinger PC, Kufera JA, et al. Crash culpability relative to age and sex for injured drivers using alcohol, marijuana or cocaine. Annu Proc Assoc Adv Automot Med 2005; 49: 327-41.

[14] Dussault C, Brault M, Lemire AM, Bouchard J. The role of cocaine in fatal crashes: first results of the Quebec drug study. Annu Proc Assoc Adv Automot Med 2001; 45: 125-37.

[15] Movig KL, Mathijssen MP, Nagel PH, et al. Psychoactive substance use and the risk of motor vehicle accidents. Accid Anal Prev 2004; 36: 631-6.

[16] Ditter SM, Elder RW, Shults RA, et al. Task Force on Community Preventive Services. Effectiveness of designated driver programs for reducing alcohol-impaired driving. Am J Prev Med 2005; 28(5 Suppl): 280-7.

[17] Elliott MR, Shope JT, Raghunathan TE, et al. Gender differences among young drivers in association between high-risk driving and substance use / environmental influences. J Stud Alcohol 2006; 67: 252-60.

[18] Couper MP. Web surveys: a review of issues and approaches. Public Opin Q 2000; 64: 464-94.

[19] Buchanan T. Online assessment: desirable or dangerous? Prof Psychol Res Pract 2000; 33: 148-54. 
[20] Barry D. Assessing culture via the internet: methods and techniques for psychological research. CyberPsychol Behav 2001; 4: 17-23.

[21] Gosling SD, Vazire S, Srivastava S, et al. Should we trust webbased studies? A comparative analysis of six preconceptions about Internet questionnaires. Am Psychol 2004; 59: 95-104.

[22] Holmes S. Methodological and ethical considerations in designing an Internet study of quality of life: A discussion paper. Int J Nurs Stud 2009; 46: 394-405.

[23] Shih T-H, Fan X. Comparing response rates from web and mail surveys: a meta-analysis. Field Method 2008; 20: 249-70.

[24] Couper MP, Blair J, Triplett T. A comparison of mail and e-mail for a survey of employees in federal statistics agencies. J Off Stat 1999; 15: 39-56.

[25] Van Loon AJM, Tijhuis M, Picavet HSJ, et al. Survey nonresponse in the Netherlands: effects on prevalence estimates and associations. Ann Epidemiol 2003; 13: 105-10.

[26] Verster JC, Kuipers E, Kuerten Y, et al. Risk taking behavior and decision to drive a car after using alcohol and/or cocaine: validation of the RT-18 risk taking questionnaire. J Psychopharmacol 2009; 23 (supplement to \#6): A37.

[27] Eysenck SGB, Pearson PR, Easting G, et al. Age norms for impulsiveness, venturesomeness and empathy in adults. Pers Individ Dif 1985; 6: 613-9.

[28] Lijffijt M, Caci H, Kenemans L. Validation of the Dutch translation of the I7 questionnaire. Pers Individ Dif 2005; 38: 1123-33.

[29] Cloninger CR, Svracik DM, Przybeck TR. A psychobiological model of temperament and character. Arch Gen Psychiatry 1993; 50: 977-91.

[30] Duijsens IJ, Spinhoven P, Goekoop JG, et al. The Dutch temperament and character inventory (TCI): dimensional structure, reliability and validity in a normal and psychiatric outpatient population. Pers Individ Dif 2000; 28: 487-99.

[31] Zuckerman M, Kuhlman DM, Hornquist M, et al. Five (or three) robust questionnaire scale factors of personality without culture. Pers Individ Dif 1991; 23: 929-41.

[32] Sobell LC, Sobell MB. Alcohol Timeline Followback Users' Manual. Toronto, Canada: Addiction Research Foundation 1995.

[33] Seppa K, Lepisto J, Sillanaukee P. Five-shot questionnaire on heavy drinking. Alcohol Clin Exp Res 1998; 22: 1788-91.
[34] Aertgeerts B, Buntinx F, Ansoms S, et al. Screening properties of questionnaires and laboratory tests for the detection of alcohol abuse or dependence in a general practice population. Br J Gen Pract 2001; 51: 206-17.

[35] Kahler CW, Strong DR, Read JP. Toward efficient and comprehensive measurement of the alcohol problem continuum in college students: The brief young adult alcohol consequences questionnaire. Alcohol Clin Exp Res 2005; 29: 1180-9.

[36] Verster JC, Van Herwijnen J, Olivier B, et al. Validation of the Dutch Brief Young Adult Alcohol Consequences Questionnaire (BYAACQ). Addict Behav 2009; 34: 411-4.

[37] Heather N, Gold R, Rollnick S. Readiness to change questionnaire: user's manual. National Drugs and Alcohol Research Centre: University of New South Wales 1991.

[38] Defuentes-Merillas L, De Jong CAJ, Schippers GM. Reliability and validity of the Dutch version of the Readiness to Change Questionnaire. Alcohol Alcohol 2002; 37: 93-9.

[39] Rollnick S, Heather N, Gold R, et al. Development of a short 'readiness to change' questionnaire for use in brief, opportunistic interventions among excessive drinkers. Br J Addict 1992; 87: 743 54.

[40] McCormick IA, Walkey FH, Green DE. Comparative perceptions of driver ability - a confirmation and expansion. Accid Anal Prev 1986; 18: 205-8.

[41] Derogatis LR. Brief Symptom Inventory. Baltimore, MD: Clinical Psychometric Research 1975.

[42] De Beurs E, Zitman FG. The Brief Symptom Inventory (BSI): the reliability and validity of a brief alternative of the SCL-90. Maandblad Geestelijke Volksgezondheid 2006; 61: 120-41.

[43] Derogatis LR, Spencer PM. The Brief Symptom Inventory (BSI): Administration, and Procedures Manual-I. Baltimore, MD: Clinical Psychometric Research 1982.

[44] Derogatis LR. BSI Brief Symptom Inventory. Administration, Scoring, and Procedures Manual. $4^{\text {th }}$ ed. Minneapolis, MN: National Computer Systems 1993.

[45] Statistics Netherlands, Statline Databank, www.statline.cbs.nl, [Assessed on October 20, 2009]..

[46] Peduzzi P, Concato J, Kemper E, et al. A simulation study of the number of events per variable in logistic regression analysis. J Clin Epidemiol 1996; 49: 1373-9.

(C) Verster et al.; Licensee Bentham Open.

This is an open access article licensed under the terms of the Creative Commons Attribution Non-Commercial License (http://creativecommons.org/licenses/by$\mathrm{nc} / 3.0 /$ ) which permits unrestricted, non-commercial use, distribution and reproduction in any medium, provided the work is properly cited. 